\title{
A Study on the Application of STP Marketing Strategy in the MBA Education Program of Universities in China
}

\author{
Hongyi Zhang \\ School of Business Management, Shandong University of Finance, Jinan 250014, China \\ Tel: 86-159-6526-2966 E-mail: yxiaoshui@163.com
}

\begin{abstract}
The MBA education has begun in America and now it has become mature after nearly one hundred years' development. Although China's MBA merely has a history of 17 years, it has already gained great achievements. In 1991, 9 universities in China had MBA program and 86 students enrolled in. In 2007, the two numbers were 127 and 59,776 respectively. The law of things' development is to progress in a wave style and to rise in a spiral way. China's MBA education is not an exception. In 2002, the enrolling number was 67,506, being the highest ever. In 2003 and 2004, the number decreased heavily, respectively reducing 16 percent and 13 percent. From 2005 to 2007, the number increased with a rate of 9 percent, 3 percent, and 6 percent respectively. The development of MBA in China's universities has experienced a process of taking reference, exploring, developing, and regulating. In the aspects of teaching materials and methods, it chiefly takes references from experiences of universities in developed countries, such as America. In the aspects of enrollment and popularization, it makes a series of effective explorations based on China's practical situation and others' experiences. The application of STP marketing strategy exerts an extremely important driving effect on the development of China's MBA program.
\end{abstract}

Keywords: China, MBA program, STP marketing strategy, Application research

\section{The development trends of international MBA education}

\subsection{A significant decrease of applicants}

Since 2002, applicants for the school of business in North America have been reducing significantly. And in some universities, the decreasing rate has even reached 50 percent. The school of management in Europe and Australia suffers from similar situation. Accordingly, full-time students are reducing but part-time students increasing. Expense of MBA is increasing continuously. The expense in top business school has risen 55 percent during past six years. The average expense reached 33,774 dollars each year. In 2004, the expense of MBA in Harvard Business School rose to 39,000 dollars per year. And the applicants were reducing by 16 percent comparing with that in 2003.

\subsection{Main reasons for the reduction of applicants}

(1) Structure of population: the population of people between 25 and 34 years old decreases by 5 percent or so;

(2) Increasing opportunity cost for foreign students studying MBA in America;

(3) Visa;

(4) Reducing opportunity of finding a profession in America;

(5) Better work opportunity in China and India;

(6) Problems in management education. (Resource: Economist)

\subsection{Constructive suggestions}

Although MBA has developed many years and gained great achievements in the world, changing environment becomes a barrier for its further development in many aspects. Some men of insight put forward constructive suggestions. In their opinions, MBA suffers from many problems, such as teaching useful management techniques, cultivating leaders, constructing morals and regulations, guiding students to find better jobs, and increasing expenses. These suggestions and criticism become the third tide since the two reforms in 1959 and 1984. Three most important articles are from professors of business school. Bennis, the president of the leadership center in Harvard Business School, delivered "How Business Schools Lost Their Ways?" in Harvard Business Review (May, 2005). Professor Jeffery Pfeffer in Stanford Graduate School of Business published "The end of business school" in Academy of Management Learning \& Education (September, 2002). Professor Mintzberg in Business School of McGill University released the Managers Not 
MBAs in June 2004.

\section{Analysis on China's MBA development}

MBA has developed 17 years in China. Under the guidance of the Degree Office of State Council and the Direction Committee of National MBA Education, MBA has grown from none to existence, from small to large, from nothing to something, from crazy to ration, from luxury to simple, from fast-speed development to regression, from sharp decrease to stable increase. As one of 18 special degrees, MBA has contributed a lot to China's degree development. According certain people, China's MBA develops best in all kinds of high education considering its enrollment, popularization, teaching management, and students management. However, we should notice that China's MBA still can not meet the social and economic needs completely. Comparing with developed countries, China's MBA deserves greater improvement in many aspects.

2.1 China's MBA has both differences and similarities with that in European countries and American countries (Table 1).

\subsection{MBA has gained great achievements.}

(1) Applicants number is increasing fast. In 1997, 16,507 applicants took the first national MBA entrance examination. In 2002 , the number reached 67,506 , increasing by four times. The average increasing rate was 33 percent during the five years (Figure 2).

(2) MBA has kept on improving the education quality and won wide social acceptance. Professional positions of learners have been significantly enhanced after their graduation four years. So do their salaries. According to data from the world top ten business schools in 2005 (except Beijing International MBA Programs at Peking University and Euro-China International Business College), the average salary of the full-time MBA learners who graduated in 2001 reaches 179,000 Yuan per year and the average salary of the part-time MBA learners who graduated in 2001 reaches 206,000 Yuan per year, being three times of their former salaries respectively (resource: Forbes (April, 2005)). (Figure 3)

(3) Universities that have MBA program have accumulated rich experiences in enrollment, curricula arrangement, student activities, international cooperation, management and services.

\subsection{Some important trends of MBA education}

(1) The applicants of MBA decreased in 2003 and 2004. In 2003, the applicant number was 56,964, decreasing by 16 percent comparing with that in 2002. In 2004, the applicant number was 49,545, decreasing by 13 percent comparing with that in 2003. Two levels of reasons contribute to the number decrease. One is facial, namely the education separation and the employment. The other is profound, namely the MBA itself.

(2) From 2005 to 2007, the applicants are increasing slowly. Two fundamental reasons contribute to this increase. On one hand, the society needs MBA, which leads to a rational regression of MBA. On the other hand, universities apply the STP marketing strategy to the enrollment and popularization of MBA programs.

\subsection{The economic characteristics of China's MBA education market and its effects on the market}

Positive effects:

Firstly, the entrance barrier restricts vicious competition. Universities will face a difficult barrier if they plan to enter the MBA education market because of the certificate and evaluation system for the qualification of MBA education. By this way, the vicious competition that has ever appeared in China's reform and open policy is effectively avoided.

Secondly, the border characteristics of market provide with living and developing space for new MBA programs in other universities. One is the geographic border. Many full-time applicants who come from provinces where MBA education does not develop well choose to study in universities in Beijing and Shanghai. In recent years, due to the increasing pressure from job-hunting and the improved rationality in consumption, more and more applicants choose to study in universities that locate nearly. Therefore, some provincial universities that obtain the qualification of MBA education later gain more living space. The other is the border of specialization. Many applicants take the advantage specialties as well as universities' comprehensive order into consideration as they choose certain universities. For applicants who emphasize specialties, such as accounting and finance, they think a lot of specialties and curricula. Therefore, some provincial universities and other universities that possess advantage specialties gain certain competitive advantages.

Negative effects:

Firstly, the market need is poor and the competition is lack of order. The social demand for MBA is small and MBA applicants are less. However, many universities provide with MBA programs. The competition among universities does not follow any rule. As a result, the fame of MBA is destroyed due to the bad management. All these facts determine a fierce competition in China's MBA market, which directly leads to such a result that many universities fail to absorb 
sufficient MBA applicants. In many universities, the one-diploma MBA applicants are too less to form one class. Therefore, they have to wait till autumn and learn together with two-diploma MBA applicants.

Secondly, the state system and the management mechanism are fixed (except Euro-China International Business College and Cheung Kong Graduate School of Business), what fails to drive the development of MBA program further. Because universities in China are kind of state-owned public causes, their flexibilities in management are limited. Besides, comparing with the education of undergraduates and graduates, MBA program is merely a small part of things in universities. Universities usually pay more attentions on the formers. They put the MBA education at an inferior position. As a result, the MBA programs in universities can't obtain necessary human resources, materials, and finance to sustain its further development.

\subsection{An analysis on the five competitive forces in MBA market}

In some provinces and regions, less university has the qualification of MBA education. Therefore, some second-class universities in educational developed cities, such as Beijing, Shanghai, Xi'an, and Wuhan, recruit students from these provinces and regions. And the Degree Office of National Council continues to authorize other universities to enter the MBA education market. The Ministry of Education continues to add new degrees for specialties. Students do not familiarize well with MBA knowledge and degree. Many problems exist in the cultivation of specialty degree. And the society holds bias toward the specialty degree. Therefore, the competition in China's MBA education market is extremely severe.

Present competitors. There are five universities that are qualified by MBA education, namely Shandong University, Ocean University of China, Shandong University of Finance, Shandong Economic University, and Qingdao University (added in 2007). Besides, the well-known universities step out of their campus and popularize themselves. At present, there are at least ten famous universities that locate in Beijing and Shanghai, which have students recruiting agencies in Shandong and teach in Shandong.

Social needs. The social evaluation on MBA walks through a devious road, from not understanding, or not accepting, to overheated, then becoming cold. Until last year, the social recognition toward MBA education becomes rational. However, the first bad impression is hard to be changed. And because of the short history of MBA education in China, there are many problems in its development. Therefore, the society questions the value of MBA education, which directly leads to the sharp decrease of social needs (Figure 4).

Substitutes. Along with the continuous development of education, more and more universities apply for qualification of other specialty degree. The School of Business Management of Shandong University of Finance is not an exception. This phenomenon serves as a threat for MBA education since it usually recruits students by finance and taxation resources.

New joiners. In 2007, three universities in Shandong will obtain the qualification of MBA education. As a result, Jinan and Qingdao will possess three universities that have MBA program respectively. And Tai'an will have one university that has MBA program. Along with the development of economy and education, the state will authorize new universities to provide with MBA education, which will make the competition more severe.

Applicants. Today, applicants have higher ability of bargaining. The first reason is for more optional universities. The second is for more optional specialty degrees. The third is for greater pressure from job-hunting. And the anticipation of income is less. They become sensitive to expenses.

Therefore, present MBA education market is a battlefield. The MBA program in Shandong University of Finance confronts with great pressure from competition. We should hold an open idea, make exploration and innovation, and realize flexible operation and management. By this way, we can achieve survival and gain further development.

\section{Research on the application of STP marketing strategy}

\subsection{Constitution of marketing strategy}

(1) Market segmentation. Based on the macro situation, including national politics, economy, and culture, and the analysis on self advantages and disadvantages in teaching features, quality of teachers, hardware and facilities, we can make market segmentation toward the MBA applicants. Market segmentation may be based on industries, such as processing and manufacturing industry, communication and transportation industry, finance industry, energy industry, pharmaceutical industry, commerce industry, restaurant and service industry. In market segmentation, we should consider the situation in competitors, including both similar universities and non-similar universities. Differentiate the target market as much as possible and avoid over competition in one region. Market segmentation may be based on regions, such as this province and other provinces, the east, middle, or west of this province, large- and medium-cities, and small- and medium-cities. And the market segmentation can also be based on the management levels of applicants, such as middle- and top-mangers, middle- and lower-managers. And it may be based on the development of economy, such as developed regions, less-developed regions, and undeveloped regions. It may also be based on ages, such as 
under-30 years old, between 30 and 40, between 40-50, etc.

(2) Target establishment. Find out the target customers in focus marketing and set up target products for them, namely the curricula modes. The set-up of curricula mode should completely embody the features of teaching and specialties in the university. The names and contents of courses, the uses of textbooks and cases, the teachers, the arrangement of classrooms, and many other elements should reflect the characteristics of customers' industry and consider the situation of target industry.

(3) Position. Position the levels of target customers, what is important. In MBA program, universities and learners make choices mutually. Universities should choose target customers whose management levels meet their educational capabilities. It is not necessarily to recruit all applicants who hold top positions in management. Position the region. Universities should position the main target region according to their locations, and determine whether recruit students from other regions. Position the expense finally. Universities should establish the MBA expenses according to their own situations, customers' financial strengths, and the MBA expenses of competitors.

\subsection{The application of marketing strategy}

After establishing the marketing strategy, the next step is to perform a series of marketing activities, such as constituting the recruiting and popularizing plan, programming the advertising activities and making budget, printing propagandizing manuals, making plane advertisement in proper position, advertising in relevant media, and planning to hold an introduce meeting for the recruitment. Propagandizing is a daily work in a sense. And it is better to hold an introduction meeting before the signing date.

\subsection{The STP marketing strategy and MBA brand construction}

An important standard used to judge whether a MBA program gains success or not is the brand. The brand construction is based on sufficient applicants. Quality and features are two main contents for brand construction. Advertising for recruitment is a chief way for customers accepting universities, what is an important part of teaching quality in universities and also a main way to report the features of universities. Resources of universities are limited. In an environment with fierce competition, target customers possess great freedom in choosing certain university. Universities must position their target customers properly, which will help them obtain sufficient applicants. Therefore, the STP marketing strategy in China exerts a vital effect on the success of MBA program in universities.

\section{References}

Chen, Xiao. \& Shen, Zuyun. (2003). MBA in China: Problems are solved in development. China Education News. 12th, Nov.

Henry Mintzberg. (2006) Managers Not MBAs: A Hard Look at the Soft Practice of Managing and Management Development [M]. Canada: Berrett-Koehler Publishers,Inc.

Kulwant Singh. Translated by Lv, Wei. (2005). Strategic Management. Beijing: China Machine Press.

Philip Kotler. (2001). Marketing Management. Prentice Hall.

Wu, Shinong. \& Tong, Yunheng. (2001). Practices and Exploration on China's MBA Education. Beijing: China Machine Press.

Yang, Bin. (2005). Things that can be Learned from MBA and Things that can not ----- A Self- Examination by the School of Business Administration. Beijing: Tsinghua University.

Yang, Shanshan. \& Ni, Weiqian. (2005). The most valuable business school in China in 2005. Forbes. No.4.

Zhao, Chunjun. (2003). Problems in the development of MBA in China and the countermeasures. Reports of MBA Education in China. 
Table 1

\begin{tabular}{|c|c|}
\hline China & Europe and America \\
\hline Initial stage of economic development & Developed stage of economic development \\
\hline A history of 16 years & A history of 99 years \\
\hline Initial stage of MBA & Thousands of MBA programs \\
\hline 96 MBA programs & 100,000 graduates per year \\
\hline 18,000 graduates per year & Higher quality and education degree of managers \\
\hline $\begin{array}{c}\text { Leak basic management and fast development speed } \\
\text { in enterprises }\end{array}$ & $\begin{array}{c}\text { Strong basic management and low development speed } \\
\text { in enterprises }\end{array}$ \\
\hline
\end{tabular}

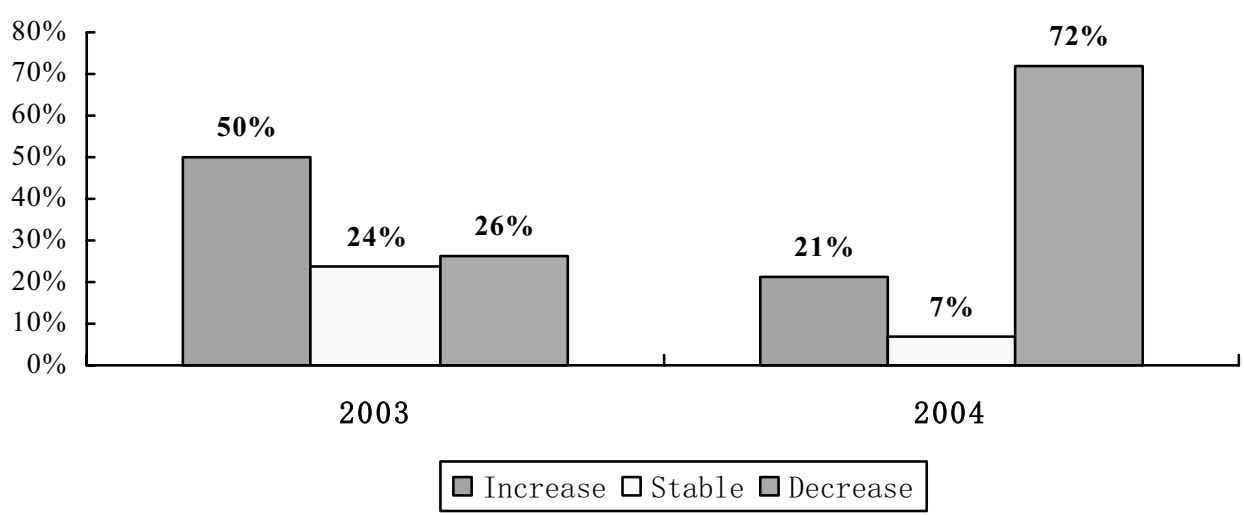

Figure 1. Changes of Full-Time Management Education Applicants Number in all Business Schools of America from 2003 to 2004.

Resource: Graducate Management Admission Council, USA (Bin Yang, 2005).

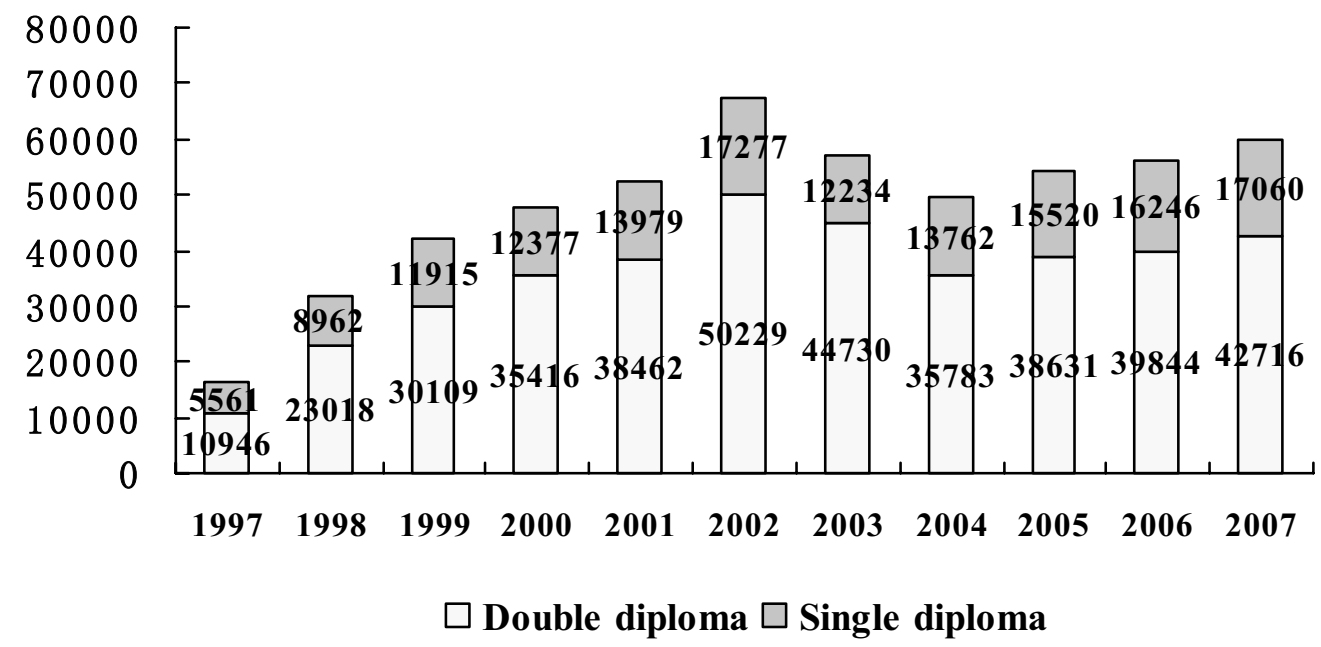

Figure 2

Resource: The Secretariat of the Direction Committee of National MBA Education 


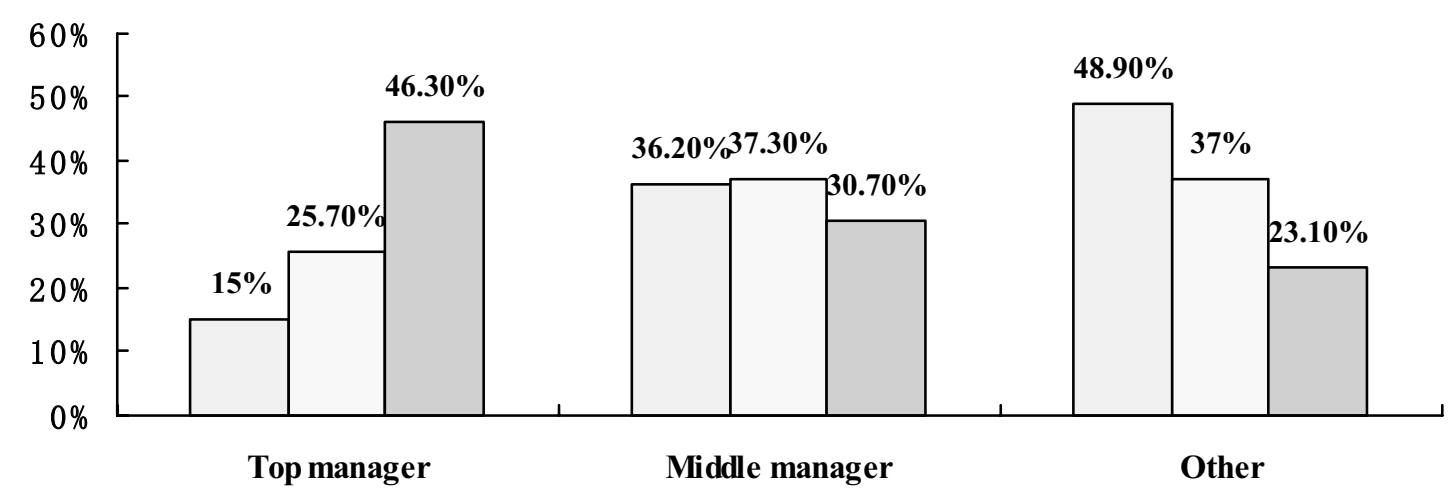

$\square$ Before $\square$ After graduation one year $\square$ After graduation four year

Figure 3

Resource: The Secretariat of the Direction Committee of National MBA Education

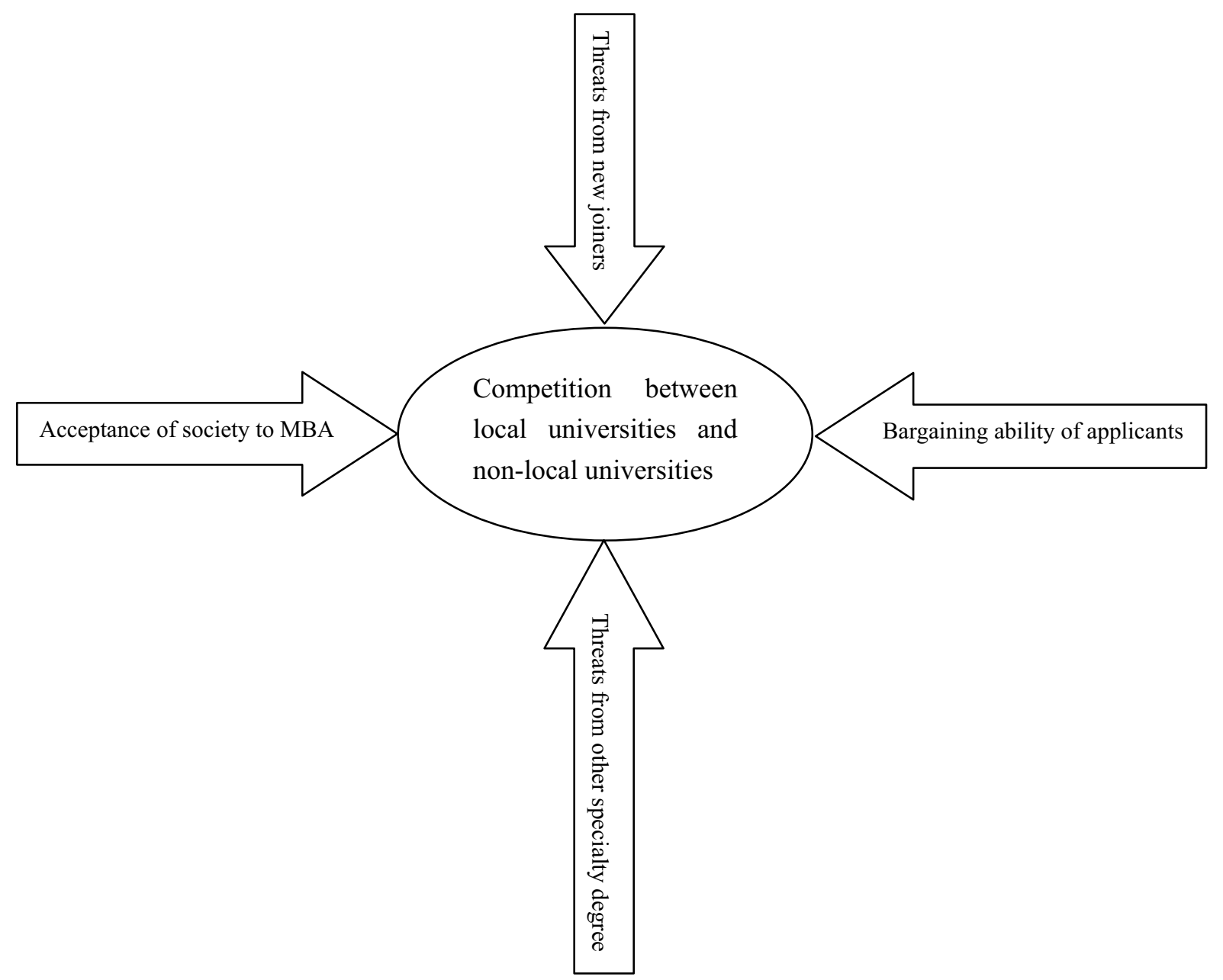

Figure 4 